\title{
ARTE RUPESTRE EN EL ESTRET DE LES AIGÜES (BELLÚS-XÀTIVA, VALENCIA)
}

\author{
MAURO S. HERNÁNDEZ PÉREZ \\ Universidad de Alicante \\ PERE FERRER I MARSET \\ ENRIQUE CATALÁ FERRER \\ Centre d'Estudis Contestans (Cocentaina, Alicante)
}

\begin{abstract}
Se da cuenta del hallazgo de dos nuevos yacimientos con arte rupestre en la provincia de Valencia. En la Cova Gran de La Petxina existen pinturas de tipo levantino y esquemáticas, que deben fecharse a partir del Neolítico Medio. En la Cova del Barranc de l'A guila los grabados de jinetes, équidos y antropomorfos son de imprecisa cronología, pero nunca prehistóricos.

Account is given of the finding of two caves or parietal art in the Valencian area. There are Levantine and Schematic paintings at the Cova Gran in La Petxina which date back to Middle Neolithic. The engravings of horsemen, horses and human figures in the Cova of Barranc de l'Aguila are difficult to date but are definitely not prehistoric.
\end{abstract}

Con ocasión de nuestras prospecciones arqueológicas en las comarcas centro-meridionales valencianas descubrimos el 24 de octubre de 1982 dos nuevos yacimientos con arte rupestre en la cuenca del Riu Albaida (1), donde H. Breuil había señalado la presencia de pinturas rupestres prehistóricas (BREUIL, 1929), que al parecer han desaparecido (PLÁ BALLESTER, 1973 a, 52 y 1973 $b, 269)$.

En uno de los yacimientos hemos constatado pinturas levantinas y esquemáticas - Cova Gran de La Petxina-, mientras en el otro sólo existen grabados de muy difícil encuadre cronológico.

(1) Colaboraron en la prospección y en la realización del calco y planimetría J.M. Albors, E. Faus, J.R. García y J. LI. Pascual.

\section{I.- COVA GRAN DE LA PETXINA}

Se ubica en la margen izquierda del Riu Albaida (figura 1), a unos 50-75 m. aguas arriba del yacimiento musteriense de la Cova de La Petxina (JORDÁ, 1947; VILLAVERDE, 1984, 214-253), donde existen restos de pinturas a una cierta altura, ambas en el Término municipal de Bellús (figura 2:2). Coordenadas: $38^{\circ} 57^{\prime} 35^{\prime \prime}$ lat. N. y $3^{\circ} 11^{\prime}$ 58 " long. E. del meridiano de Madrid.

Se trata de un gran abrigo de $26 \mathrm{~m}$. de largo y 7'50 m. de profundidad máxima. Carece de relleno y su suelo presenta un acusado buzamiento hacia el río (figura 3 y lámina I). La pared es irregular, abundando las banderas y las concreciones calcáreas de diverso grosor y color. Hemos localizado cuatro paneles de pinturas, aunque sólo dos de ellos han podido ser calcados, ya que de los otros 


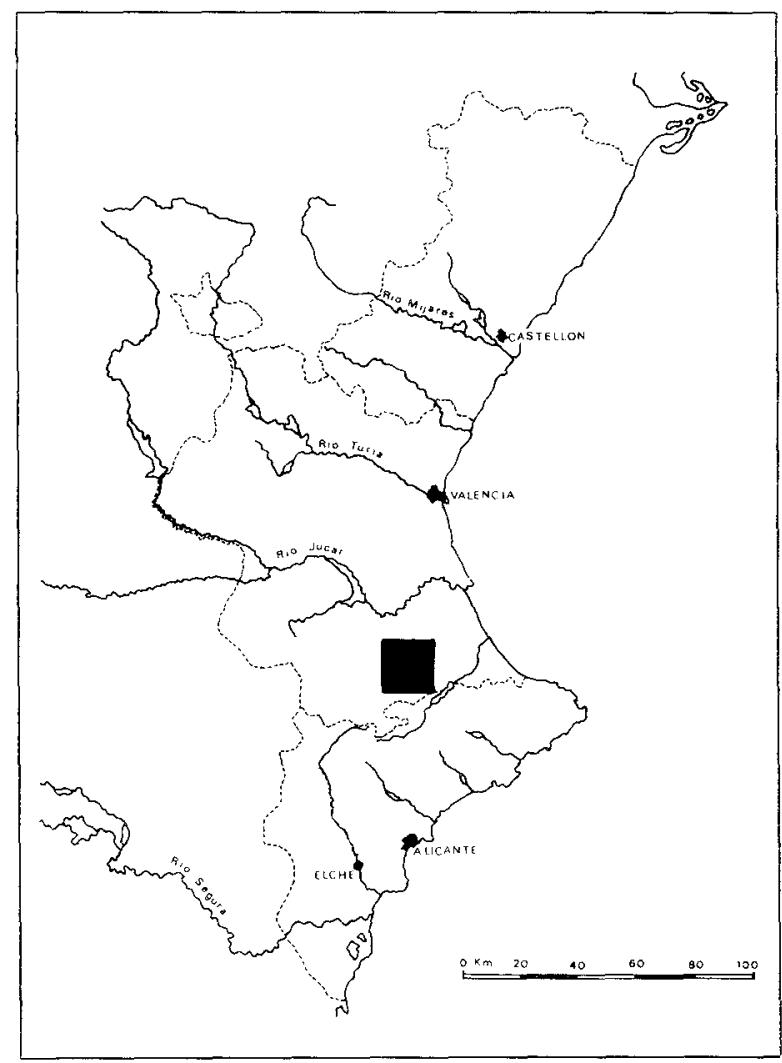

Figura 1.-País Valenciano. Se indica la situación del Estret de Les Aigües. dos - paneles 3 y 4 - las pinturas apenas son perceptibles.

\section{Panel 1}

Superficie cubierta por concreciones. Altura sobre el nivel del suelo: $2 \mathrm{~m}$. (figura 3 ).

1.1. - Restos de varias barras verticales de grosor y bordes irregulares. La mayor mide 13 ' 50 $\mathrm{cm}$. de largo. Color: M.10R 4/6.

\section{Panel 2}

Superficie cubierta por gruesas e irregulares capas de concreciones. Altura sobre el nivel del suelo desde el motivo 2.5: 1'60 m. (figura 5). A derecha e izquierda del panel existen restos de barras de tendencia vertical, no calcadas y de color M.10R 4/8 - M.10R 5/8.

2.1.- Restos de una figura humana de tipo levantino, a juzgar por el tratamiento del tronco $y$ piernas, en las que parecen indicarse los abultamientos musculares. No conserva la cabeza ni adornos corporales. Color: M.10R 3/4.

2.2. - Barra vertical de $9^{\prime} 6 \mathrm{~cm}$. de largo, de bordes irregulares. Color: M.10R 4/8.

2.3.-Pequeña mancha. Color: negro.

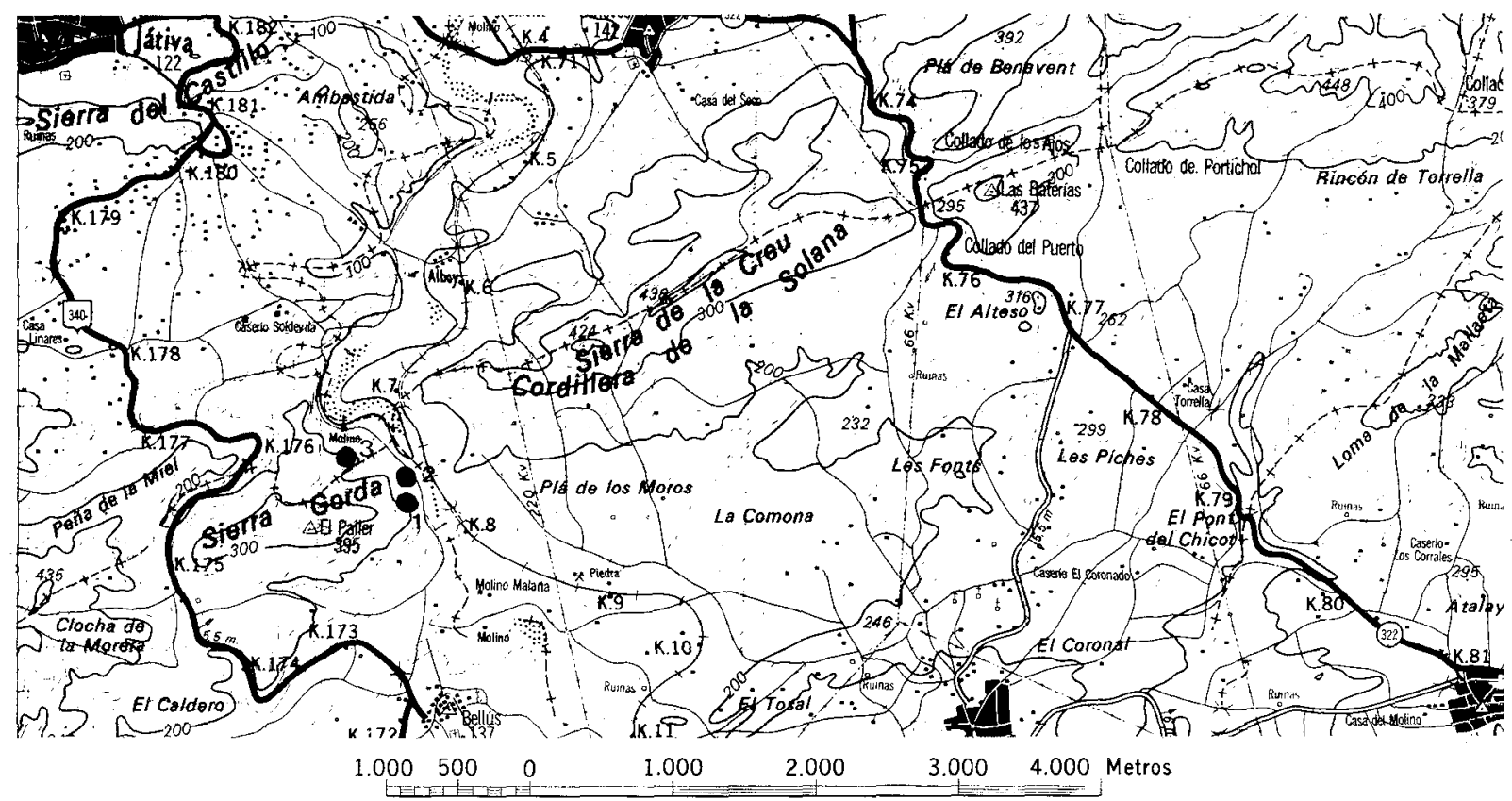

Figura 2.--Situación de los yacimientos. 1: Cova de La Petxina. 2: Cova Gran de La Petxina. 3: Cova del Barranc de l'Aguila. 


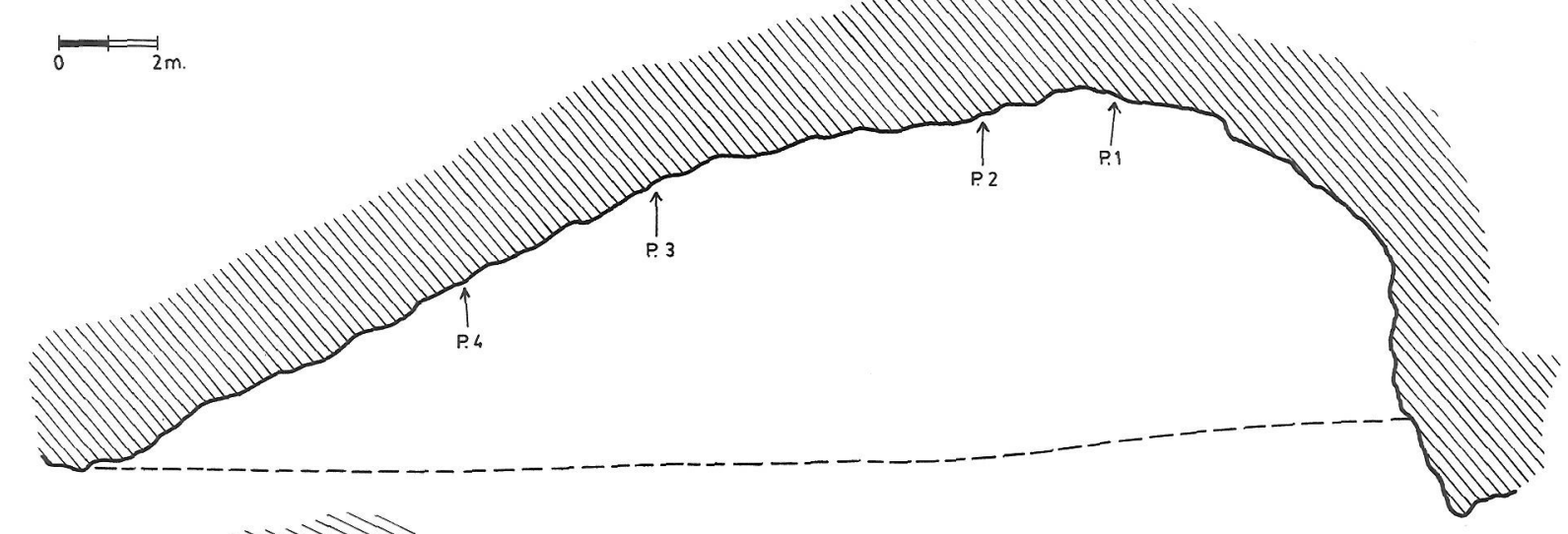

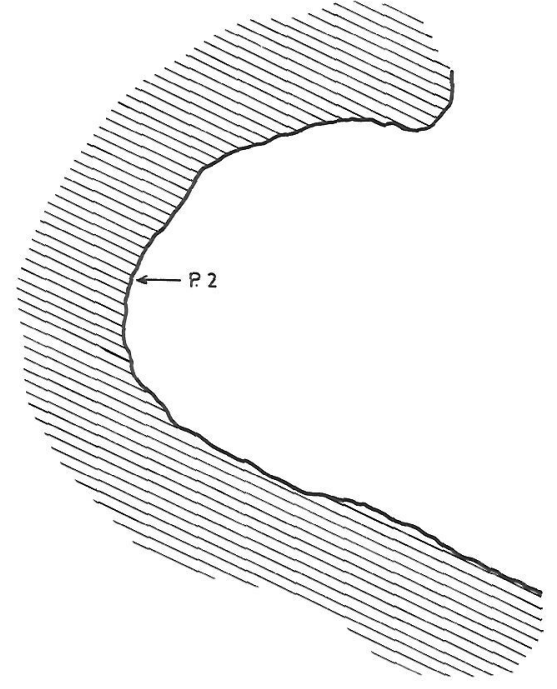

Figura 3.-Cova Gran de La Petxina. Planimetría y sección.

2.4.-Figura humana esquemática de tipo cruciforme con los brazos ligeramente inclinados hacia abajo. A la izquierda y a diversa altura existen varias manchas. Color: negro.

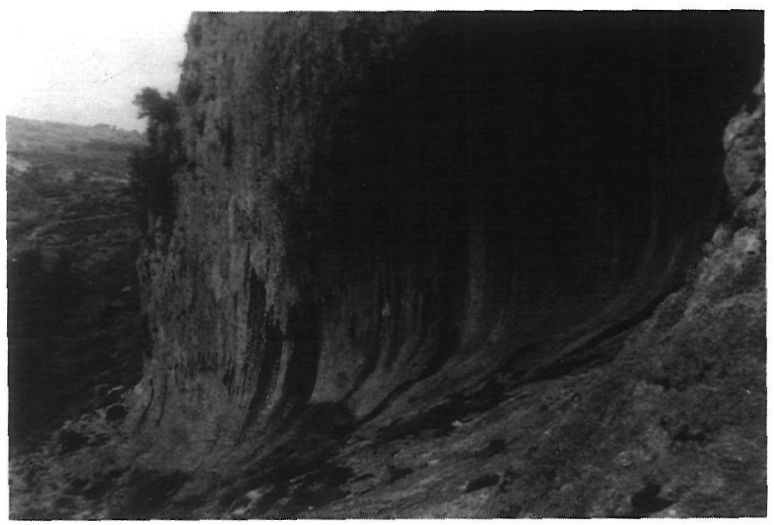

Lámina I._Cova Gran de La Petxina.
2.5.- Restos de una figura humana de tipo levantino, de la que se conserva los hombros y parte del tronco y de uno de los brazos. Debía portar varias flechas $y$, posiblemente, arco, a juzgar por los finos trazos que cruzan el tronco. Color: M.10 3/4.

2.6.--Restos de pinturas. Color: M.10 4/6.

2.7.--Figura humana de tipo esquemático. Una barra vertical de $13^{\prime} 2 \mathrm{~cm}$. forma la cabeza, ligeramente apuntada, el tronco, de contorno irregular, y el falo. Brazos y piernas se representan

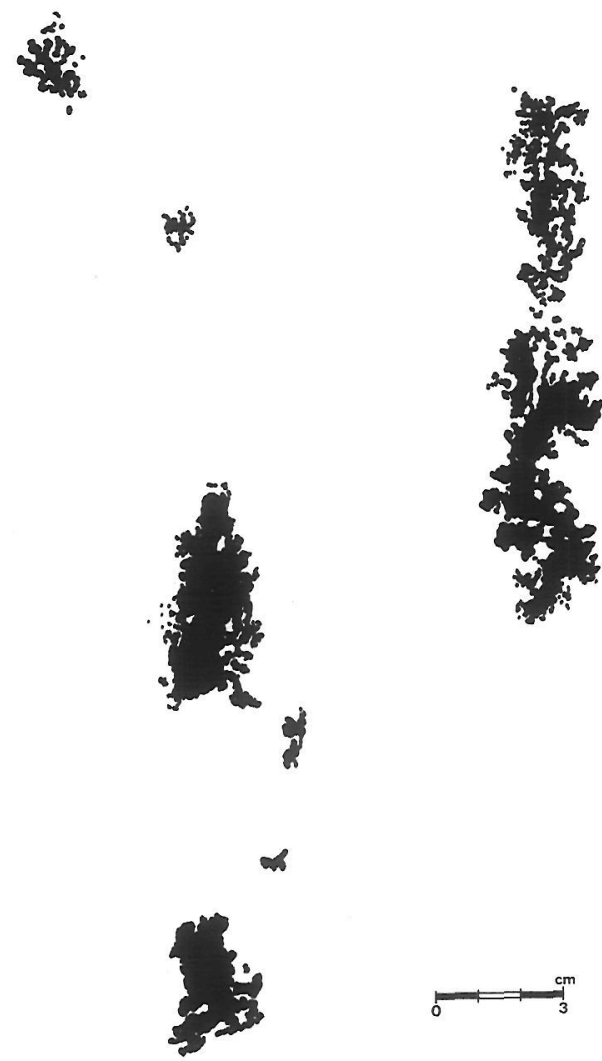

Figura 4.-Cova Gran de La Petxina. Panel 1. 


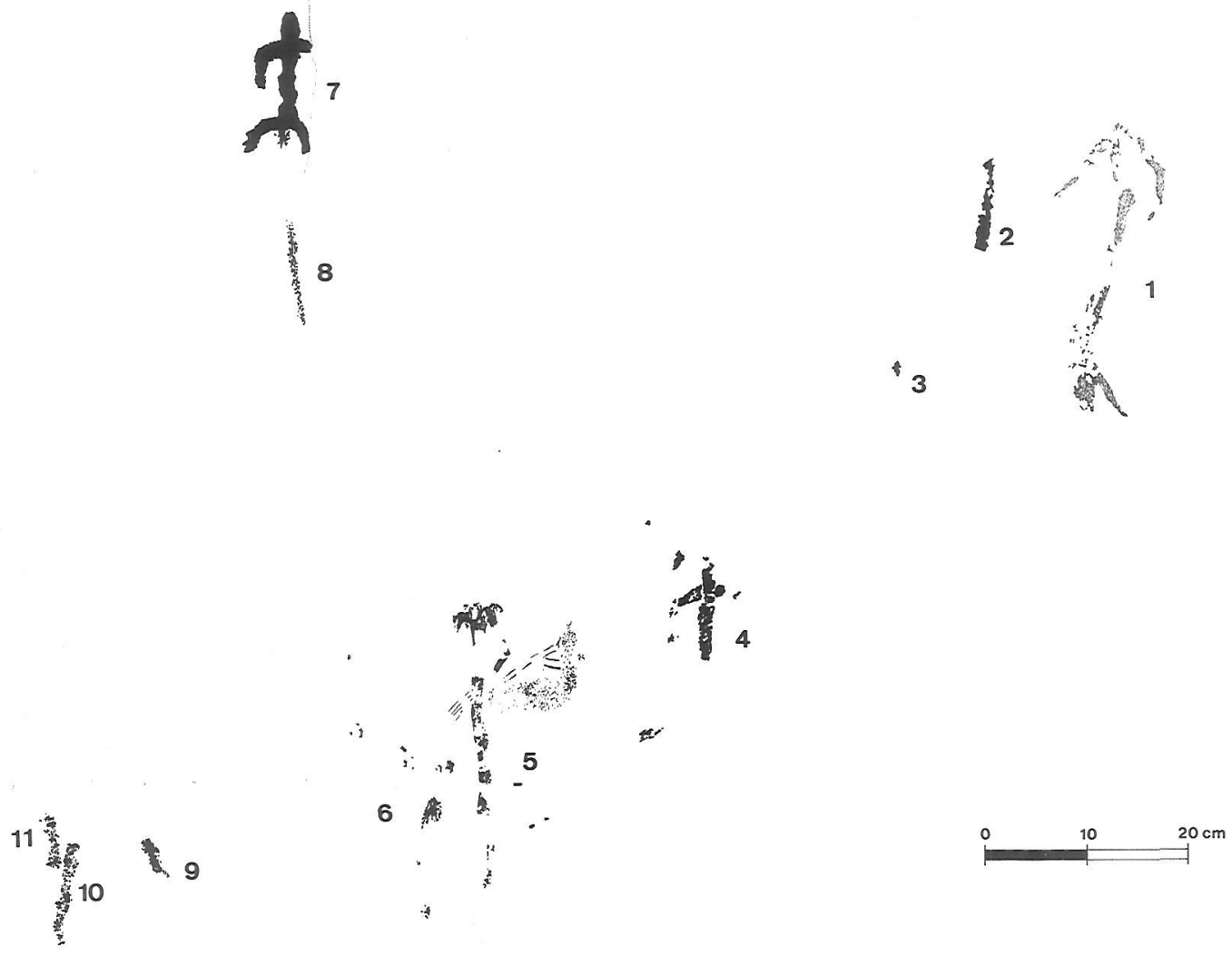

Figura 5.-Cova Gran de La Petxina. Panel 2.

mediante arcos semicirculares abiertos hacia abajo. Color: M.10R 4/6.

2.8. - Restos de una barra vertical de $10^{\prime} 5 \mathrm{~cm}$. de largo. Color: M.10R 5/8.

2.9.-Barra ligeramente oblícua, de bordes irregulares. Color: M.10R 5/8.

2.10.- Restos de una barra de tendencia vertical de $10 \mathrm{~cm}$. de largo y bordes irregulares. Color: M.10R 3/4.

2.11. - Restos de una barra de tendencia vertical de $522 \mathrm{~cm}$. de largo y bordes irregulares. Color: M.10R 5/5.

\section{II.- COVA DEL BARRANC DE L'AGUILA}

Cueva de $375 \mathrm{~m}$. de boca y $4 \mathrm{~m}$. de profundidad máxima, situada en la margen izquierda, a unos $75 \mathrm{~m}$. sobre su cauce, del Barranc de l'Aguila, tributario por la izquierda del Riu Albaida, en el Término municipal de Xàtiva (figura 2:3). Coordenadas: $38^{\circ} 57^{\prime} 42^{\prime \prime}$ lat. N. y $3^{\circ} 11^{\prime} 43^{\prime \prime}$ long. E. del meridiano de Madrid.
Una capa de excrementos de animales cubre el suelo de la cueva, utilizada como redil, del que se conserva parte del muro de cierre de la entrada (figura 5 y lámina II). Las paredes se encuentran ennegrecidas. Junto a la pared de entrada existen varias cruces de ejecución reciente, realizadas me-

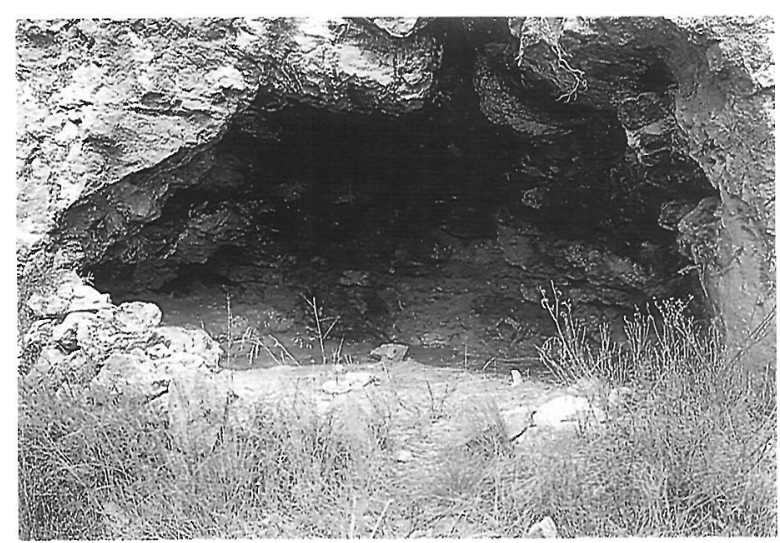

Lámina II._Cova del Barranc de l’Aguila. 


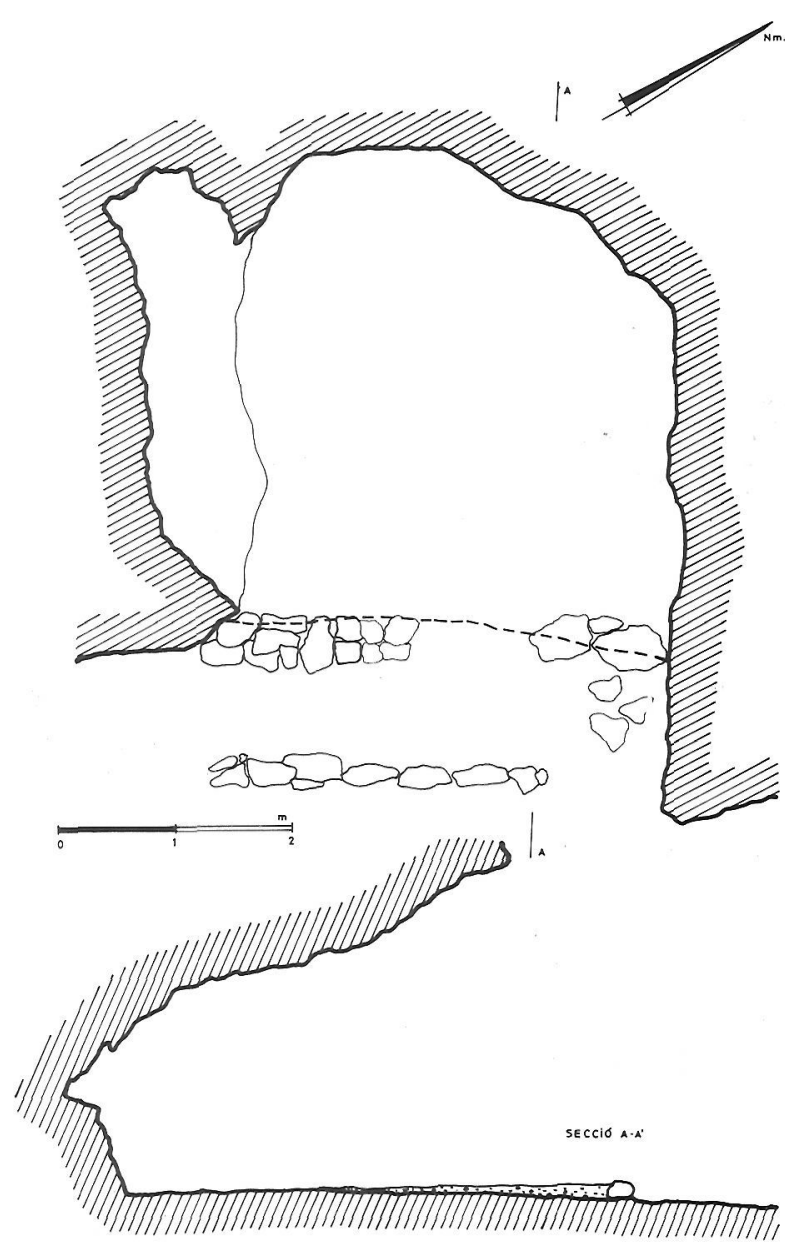

Figura 6.-Cova del Barranc de l'Aguila. Planimetría y sección.

diante superficial que deja al descubierto la roca amarillenta. El resto de los grabados presentan un aspecto muy diferente. También realizados mediante la técnica del picado, pudiéndose observar en algunos los puntos de percusión, el surco se encuentra erosionado y cubierto de una pátina grisácea.

\section{Panel 1}

Al fondo de la pared derecha. Altura sobre el nivel del suelo desde el motivo 1.3: 0'40 m. (figura 7).

1.1.- Restos de zoomorfo, en el que se indica rabo, las cuatro patas, paralelas y verticales, el tronco, una gruesa oreja o cuerno y parte de la cabeza, cortada por un desconchado.

1.2.-Dos gruesas barras e irregulares barras horizontales y otra más pequeña sobre una de ellas.

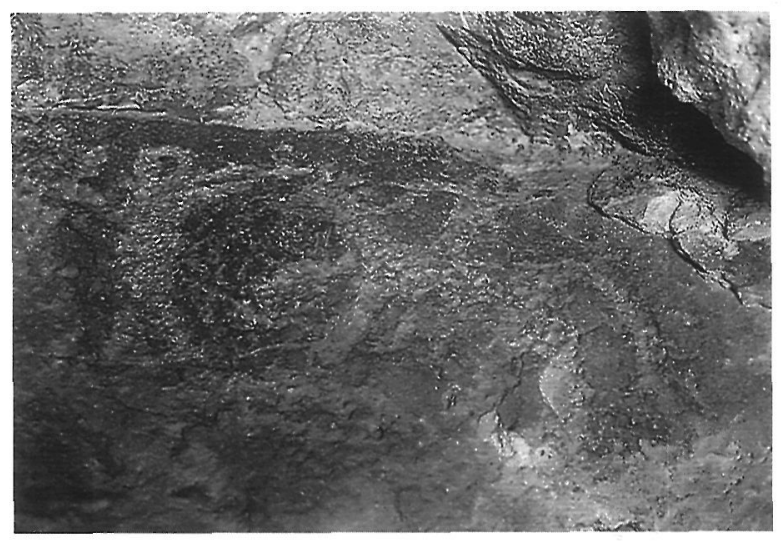

Lámina III.-Cova del Barranc de l'Aguila. Panel 1.3.

1.3.- Escena formada por un jinete a caballo, una figura humana de pié, un motivo oval y una gruesa barra vertical (lámina III). El caballo se representa en actitud de marcha, indicándosele un largo rabo levantado. Una pequeña zona en reserva podría interpretarse como el ojo del animal. El jinete, al que se le señalan las piernas, de perfil y una más gruesa que otra, sujeta el caballo mediante riendas, mientras con el otro brazo sostiene una espada, con la que parece atacar a la otra figura humana. La cabeza de ambas se encuentra en reserva. El segundo antropomorfo se representa de pié, con una pierna de perfil y la otra posiblemente de frente. Los brazos, extendidos, presentan desigual tamaño, por lo que debe llevar en uno de ellos un objeto, de difícil identificación, quizás un puñal, con el que se enfrenta al jinete. El motivo oval colocado bajo las patas del caballo podría relacionarse con una simple señalización de la línea del suelo, del que quizás también formen

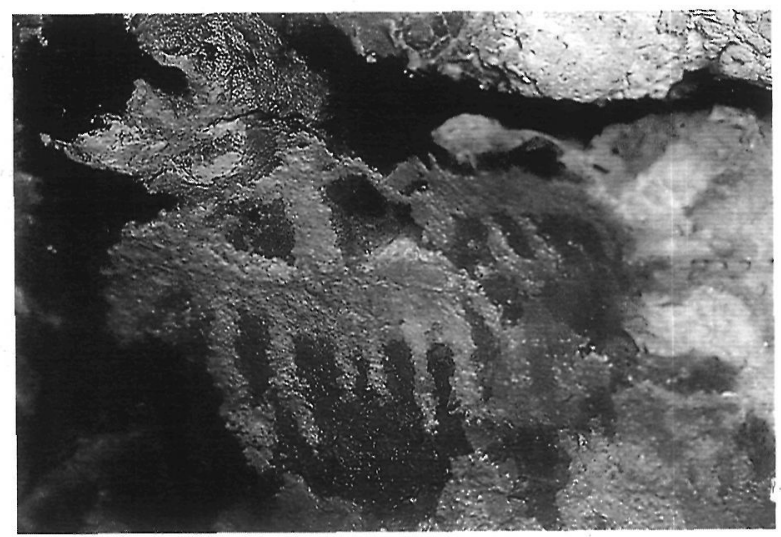

Lámina IV._Cova del Barranc de l'Aguila. Panel 2.3. 

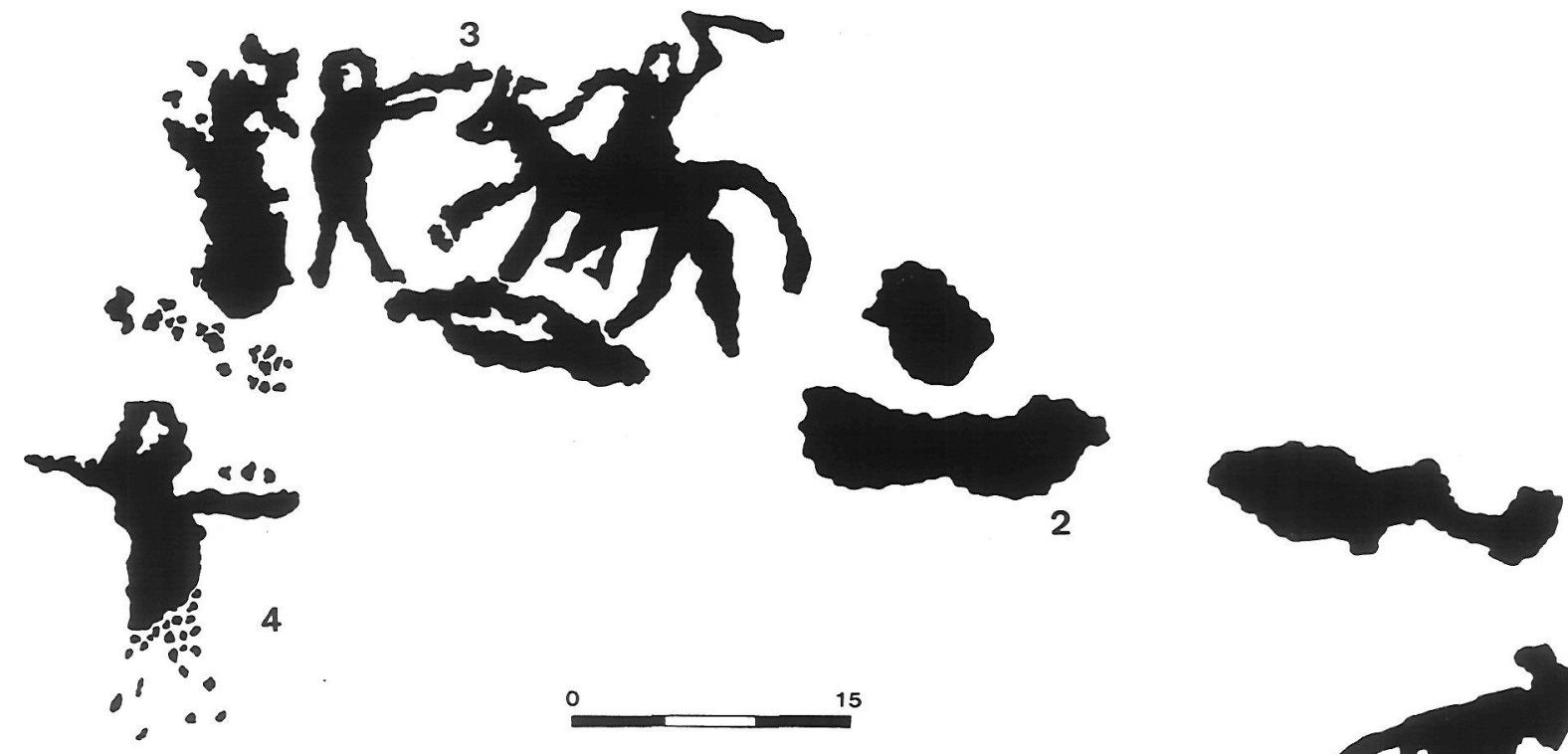

Figura 7.-Cova del Barranc de l'Aguila. Panel 1.

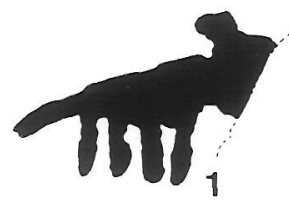

parte los motivos 1.2. Mayores dificultades de identificación ofrece la gruesa barra vertical, que cierra la escena por la izquierda, debajo de la cual existen varios puntos.
1.4. - Figura humana con los brazos extendidos en cruz con la cabeza en reserva. Las piernas en $\mathrm{V}$ abiertas hacia abajo se realizan mediante picado discontinuo.

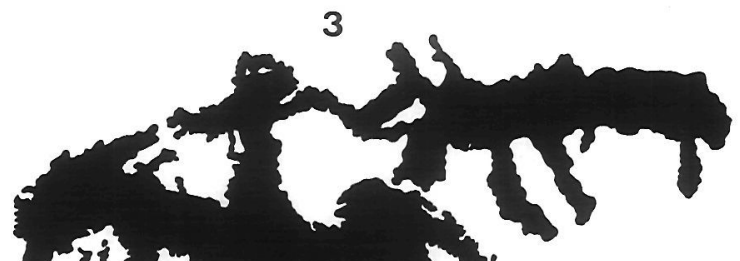

nit

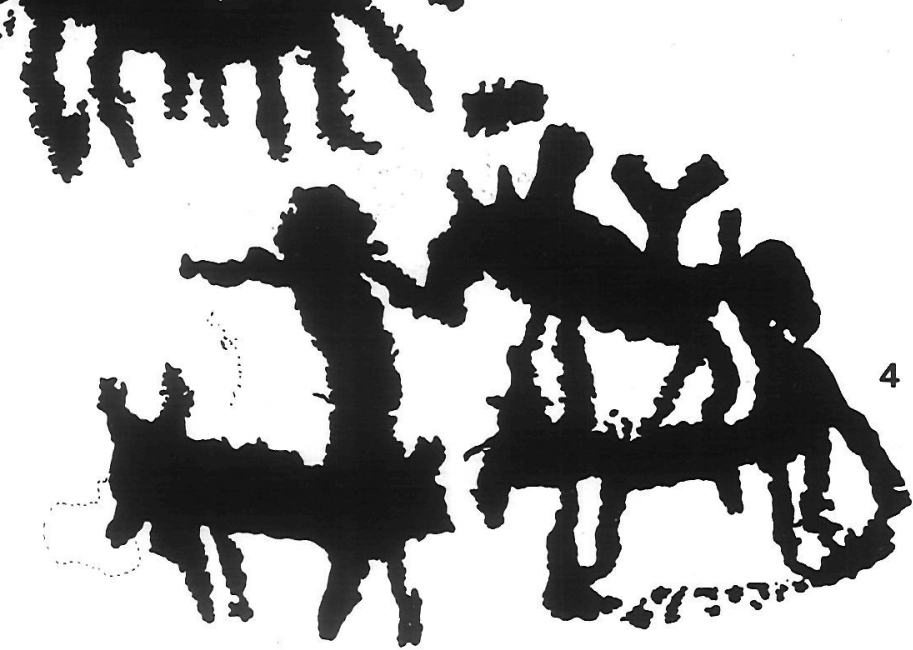

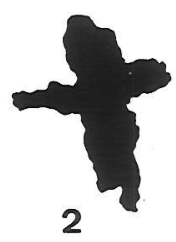

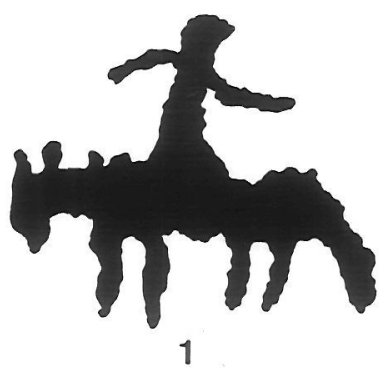

Figura 8.-Cova del Barranc de l'Aguila. Panel 2. 


\section{Panel 2}

Al fondo de la pared izquierda (figura 8).

2.1.- Jinete con los brazos extendidos montado en tosco équido, del que se indica la cabeza con dos gruesas orejas, abultamientos a la altura de la cruz, las cuatro patas y un largo y grueso rabo. No se representan las piernas del jinete.

2.2.-Cruciforme. La barra vertical es más gruesa que la horizontal.

2.3. - Escena formada por un jinete montado en un équido de muy toca ejecución, al igual que todo el conjunto. El jinete, al que se le representan las piernas, tira de otro animal de muy difícil identificación.

2.4.-Confusa escena de muy torpe ejecución. Un jinete montado en desproporcionado cuadrúpedo tira de otro animal, en el que se señalan las orejas, tres apéndices, el central en forma de $\mathrm{Y}$, perpendiculares al dorso, grueso rabo y cuatro patas. Estas últimas y el rabo se unen a la parte superior de otro cuadrúpedo, en el que parece indicarse el sexo mediante corto trazo perpendicular al vientre y cuyo rabo se prolonga en la parte baja uniendo ésta con las patas traseras y mediante un picado discontinuo con las delanteras.

\section{III.- CONSIDERACIONES FINALES}

La Cueva del Pernil era hasta este momento el único yacimiento con arte rupestre registrado en esta zona, ya que los restantes abrigos de La Vall d'Albaida, La Costera y La Safor se encuentran relativamente distantes. De la Cueva del Pernil sólo conocemos los calcos y descripción de $\mathrm{H}$. Breuil, quien señala su deficiente grado de conservación que dificulta la identificación de los motivos, por lo que reproducimos su calco (figura 9) y descripción (BREUIL, 1928, 21):

"Sur le panneau peint, et superposé à de largues bandes rouges très pâlies appartenant à de grandes silhouettes, plus anciennes, se voit à gauche, en rouge plus intense, une sorte de ramure de cervidé, formée de 4 branches très disparates; une à gauche, en grand arc de cercle, puis une plus courte, droite, une troisième, droite aussi, mais plus longue, et avec deux étages d'andouillers opposés par paires, enfin une courte bande asciforme s'évasant légèrement vers l'extrémité. Au dessous, se voit une tête à museau en pointe, une ligne de poitrail et des vestiges de ventre.

Un peu en avant et plus bas, se remarque un grand axe oblique, peut-être surmonté d'une tête,
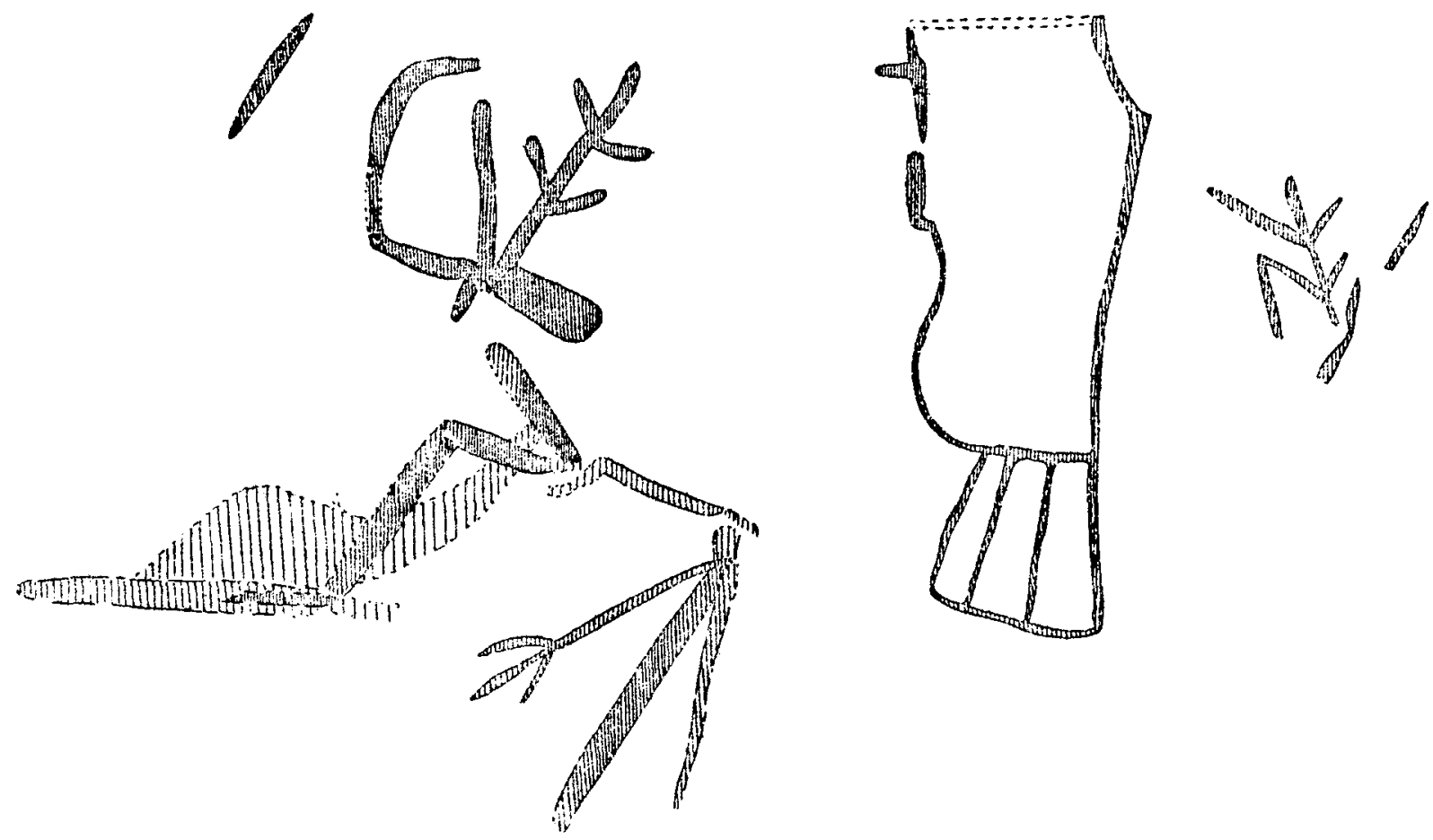

Figura 9.-Cueva del Pernil. Calco de H. Breuil. 
et du haut duquel descendent en s'éscartant 2 bras symétriques, dont le gauche se tremine en main tridentée.

Plus à droite, vient un grand motif orienté verticalement, séparé en deux segments; le supérieur, en plus mauvaise état et qui parait se terminer carrément en haut, à le côté gauche très sinueux, et le droit à peine coudé; l'inférieur est un trapèze formé de 4 traits s'écartant en éventail jusqu'a la base de la figure. J'ignore le sens de cette figure, extrèmement conventionnelle et qui s'écarte de ce que je connais. Peut-être serait-ce un grand Poison de style trés conventionnel?

A l'extrémité droite, existe encore une reste de petit rameau à double étage, ressemblant assez symétriquement à l'une des ramures de cerf précédent; comme on ne peut savoir s'il s'agit d'une figure entière ou d'un débris, toute interprétation serait risquée".

Los motivos de la Cueva del Pernil son realmente extraños. H. Breuil los consideró levantinos y sin embargo no se recogen en los inventarios de esta manifestación artística (APARICIO et alii, 1982; BELTRAN, 1968 y 1982, 9-11; DAMS 1984). En cambio, P. Acosta, pese a no ser citado este yacimiento en el corpus de Arte esquemático de H. Breuil (1932/1935), incluye en su estudio (ACOSTA, 1968, 193 y 212) una figura humana esquemática y un tectiforme.

La Cova Gran de La Petxina confirma una vez más la coexistencia en un mismo yacimiento de pinturas levantinas y esquemáticas, tal como hemos señalado en los abrigos de la provincia de Alicante (HERNÁNDEZ, FERRER y CATALÁ, 1988; MARTÍ y HERNÁNDEZ, 1988). En esa misma ocasión hemos indicado los problemas cronológicos que plantean ambas manifestaciones artísticas. Este nuevo yacimiento no ofrece nuevas aportaciones en este aspecto, ya que el deficiente estado de conservación de los dos antropomorfos levantinos dificulta su encuadre en alguna de las fases propuestas para el Arte Levantino, sobre las que, por otro lado, hemos manifestado nuestras reservas. La ausencia de adornos y objetos asociados a estos antropomorfos dificulta aún más su datación, que en el estado actual de la investigación consideramos posterior a los últimos siglos del $\mathrm{V}$ milenio a.C., a partir del tránsito de Neolítico Antiguo al Neolítico Medio.

Entre las pinturas esquemáticas de este yacimiento se constata la presencia de dos tipos de fi- guras humanas y varias barras. Estas últimas se encuentran presenten en la práctica totalidad de yacimientos valencianos con este tipo de manifestación artística y prácticamente es imposible precisar su cronología. Existen paralelos desde el Neolítico Antiguo para las figuras humanas esquemáticas (MARTÍ y HERNÁNDEZ, 1988), si bien los dos tipos de antropomorfos de este yacimiento no han sido registrado por el momento entre las cerámicas valencianas. Mayor información podemos deducir de los colores empleados. El color negro, utilizado en el antropomorfo cruciforme y en una pequeña mancha, cuando existen superposiciones en el Arte esquemático del País valenciano siempre es más reciente que el color rojo, sin que, indudablemente, se pueda precisar el tiempo que separa dichas superposiciones (HERNÁNDEZ y SEGURA, 1985, 47). Cabría, por tanto, pensar en dos momentos en la realización de las pinturas esquemáticas de la Cova Gran de La Petxina, lo que unido a la presencia de pinturas levantinas nos senala, al menos como hipótesis, tres momentos eneste yacimiento, sin que pueda descartarse, $\sin$ embargo, su coetaneidad parcial o total.

Los grabados de la Cova del Barranc de l'Aguila presentan una difícil datación. Además de los grabados solutrenses de la Cova Fosca (HERNÁNDEZ, FERRER y CATALÁ, 1988, 259) una cronología, al menos, postneolítica y posiblemente ya histórica, los ideogramas geométri$\cos$, que por el momentos se concentran en la provincia de Alicante, fechándolos, con muchas reservas, en la Edad del Bronce (HERNÁNDEZ, FERRER y CATALÁ, 1988, 285-287), y un importante conjunto de grafitos medievales y de la Edad Moderna, muy mal conocidos ya que sólo se han publicado algunos conjuntos aislados, entre los que se encuentran los de Les Roques del Mas de Molero (VIÑAS y SARRIÁ, 1985; MESADO y VICIANO, 1986), Castell de Denia (BAZZANA et alii, 1984) y Casa del Gobernador de Tabarca (BERNAT, GONZÁLEZ y SERRA, 1985).

Para los grabados de la Cova del Barranc de l'Aguila carecemos de paralelos en el País Valenciano, si exceptuamos los cruciformes, tanto los de ejecución reciente como el motivo del Panel 2.2., que podría interpretarse como figura humana $y$ por ejecución y pátina debe ser contemporáneo a los restantes antropomorfos y zoomorfos. El tema del jinete que sujeta mediante rienda a un équido está presente en una figura del Abric X de La Gasulla (RIPOLL PERELLÓ, 1962), considerada 
como del Arte levantino y que ha generado una abundante bibliografía en torno a su cronología, que se sitúa entre la Edad del Bronce (BELTRÁN, 1968, 176) y el siglo VIII a.C. (JORDÁ CERDÁ, 1985, 138). En los grabados rupestres de la Península ibérica está presente el Arte gallegoportugués, en las estelas del SW y, más próximos en el espacio, en Segovia.y Teruel. En esta última provincia los grabados del Puntal del Tío Garrillas recuerdan a algunos de la Cova del Barranc de l'Aguila, especialmente aquellos cuyo jinete se representa mediante una Y perpendicular al dorso, motivo presente en el Panel 2.4. E. Ripoll postula para estos grabados una cronología del Bronce avanzado o de época ibérica, hacia el siglo III a.C., en el que se fecha un poblado próximo (RIPOLL PERELLÓ, 1981, 151). Similar cronología se ha propuesto para algunos de los grabados segovianos de Domingo García, donde los jinetes van armados de espada y escudo (LUCAS DE VINAS, 1973, 265).

Atendiendo al armamento, los grabados de este yacimiento no pueden considerar de la Edad del Bronce, ya que en el registro arqueológico valenciano no existen espadas hasta la época ibérica. El tipo de sujeción del caballo nos lleva por otro lado a una cronología de, al menos, el I milenio a.C. Podrían fecharse en época ibérica, aunque en las cerámicas ibéricas los jinetes suelen portar lanzas o flechas en la mano y no espadas, pero también podrían fecharse en época romana, medieval e, incluso, hasta época relativamente reciente.

\section{BIBLIOGRAFÍA}

ACOSTA MARTÍNEZ, P. 1968: La pintura rupestre csquemática en España. Salamanca.

APARICIO PÉREZ, J. ct alii 1983: El primer arte vaIenciano. II. El Artc Rupestre Levantino. Valencia. BAZZANA, A. et alii 1984: Los graffiti medievales del Castell de Denia. Catálogo. Denia.

BELTRÁN, A. 1968: Arte rupestre levantino. ZaragoZa.
BELTRAN, A. 1982: De cazadores a pastores. El Arte Rupestre del Levante Español. Madrid.

BERNAT ROCA, M.; GONZÁLEZ GOZALO, E. y SERRA BARCELÓ, J. 1985: «Els graffiti de l'Illa de Tabarca (Alacant). Primeres aportacions», Canelobre, $5,112-114$.

BREUIL, H. 1929: «Vestiges de peintures préhistoriques à "La cueva del Pernil" (Játiva, Valencia)», Archivo de Prehistoria Levantina, I, 19-23.

BREUIL, H. 1932/1935: Les peintures rupestres schématiques de la Peninsule Ibérique. Lagny.

DAMS, L. 1984: Les peintures rupestres du Levant espagnol. París.

HERNÁNDEZ PÉREZ, M.S., FERRER i MARSET, P. y CATALÁ FERRER, E. 1988: Arte rupestre en Alicante. Alicante.

HERNÁNDEZ PÉREZ, M.S. y SEGURA MARTÍ, J.M. ${ }^{2}$ 1985: Pinturas rupestres esquemáticas en las estribaciones de la Serra del Benicadell, Vall d'Albaida (Valencia). Valencia.

JORDÁ CERDÁ, F. 1947: «El Musteriense de la Cova de la Pechina (Bcllús)». Trabajos Varios del S.I.P., 10, $1-8$.

JORDÁ CERDÁ, F. 1985: «El Arte prehistórico de la región valenciana: problemas y tendencias". Arqueología del País Valenciano. Panorama y perspectivas. Alicante, 121-140.

LUCAS DE VIÑAS, R. 1973: «Grabados rupestres de Domingo García (Segovia)". XII Congreso Nacional de Arqucología, 257-266.

MARTÍ OLIVER, B. y HERNÁNDEZ PÉREZ, M.S. 1988: El Neolític valenciá. Art rupestre i cultura material. Valencia.

MESADO, N. y VICIANO, J.L. 1986: «Los grabados modernos de "Les Roques del Mas de Molero" y nueva perspectiva en los estudios del arte rupestre». Centro de Estudios del Macstrazgo, 15, 7-18.

PLÁ BALLESTER, E. 1973 a: «Játiva», Gran Enciclopedia de la Región valenciana, 6, 51-53.

PLÁ BALLESTER, E. 1973 b: «Pernil, Cova del», Gran Enciclopedia de la Región valenciana, 8, 269.

RIPOLL PERELLÓ, E. 1962: «Representación de un jinete en las pinturas rupestres del Barranco del "Cingle de la Gasulla" (Castellón)», Zephyrus, XIII, 91-93.

RIPOLL PERELLÓ, E. 1981: «Los grabados rupestres del Puntal del Tío Garrillas (Término de Pozondón, Teruel)», Teruel, 66, 147-154.

VINAS, R. y SARRIÁ, E. 1985: «Los grabados "medievales" del Racó Molero (Ares del Macstre, Castellón)», Cuadernos de Prehistoria y Arqueología Castellonenses, 8, 287-289.

VILLA VERDE BONILLA, V. 1984: La Cova Negra de Xàtiva y el Musteriense de la región central del Mediterráneo español. Valencia. 